\title{
Las relaciones interamericanas durante la última década de la guerra fría. La reacción del régimen de Pinochet a la revolución sandinista $(1978-1985)^{*}$
}

\section{Inter-American Relations during the Last Decade of the Cold War. The Reaction of the Pinochet Regime to the Sandinista Revolution (1978-1985)}

\author{
Fernando Camacho Padilla** \\ (D) https://orcid.org/0000-0002-4734-9061 \\ Universidad Autónoma de Madrid, España \\ fernando.camacho@uam.es
}

Resumen: A pesar del impacto que tuvo la revolución sandinista en Latinoamérica, se desconocen las estrategias adoptadas por casi todas las cancillerías de la región. El derrocamiento de Anastasio Somoza generó en la junta militar chilena el temor de que se recrudeciera la lucha armada en el país, especialmente por la presencia de combatientes chilenos en las fuerzas sandinistas.

* Esta publicación forma parte del proyecto de investigación UAM-Comunidad de Madrid "Nuevos actores en las relaciones internacionales contemporáneas" (núm. de referencia: SI1/PJI/2019-00493).

** Doctor en Historia Contemporánea por la Universidad Autónoma de Madrid (UAM) y la Pontificia Universidad Católica de Chile en convenio de cotutela. Actualmente se desempeña como profesor de Historia Contemporánea en la UAM. Sus principales áreas de investigación se centran en la solidaridad y la militancia transnacional en el marco de la guerra fría, así como en las relaciones entre Latinoamérica y el mundo islámico durante el mismo periodo.

cómo CITAR: Camacho Padilla, F. (2020). Las relaciones interamericanas durante la última década de la guerra fría. La reacción del régimen de Pinochet a la revolución sandinista (1978-1985). Secuencia (108), e1841. DOI: https://doi.org/10.18234/secuencia.v0i108.1841

c) 98

Esta obra está protegida bajo una Licencia Creative Commons Atribución-NoComercial 4.0 Internacional. 
Además, el nuevo gobierno nicaragüense acogió a un número significativo de refugiados chilenos, algunos de los cuales ocuparon cargos gubernamentales de importancia. Por lo tanto, este artículo se centra en la política exterior de Pinochet frente a este acontecimiento, a partir de una revisión exhaustiva de fuentes inéditas procedentes de distintos archivos. El objetivo de este artículo es desentramar las estrategias adoptadas por el régimen militar para evitar que Nicaragua se convirtiera en un lugar protagónico de la solidaridad con la oposición chilena en el exterior.

Palabras clave: revolución sandinista; Chile; Pinochet; Nicaragua; guerra fría latinoamericana.

Abstract: Despite the impact of the sandinista revolution in Latin America, little is known of the strategies adopted by the foreign ministries of the region. The overthrow of Anastasio Somoza alarmed the Chilean military junta due to the possibility of a resurgence of the armed struggle in the country, especially due to the presence of Chilean combatants in the sandinista forces. Moreover, the new Nicaraguan government welcomed a significant number of Chilean refugees, some of whom were given senior government positions. This article therefore focuses on Pinochet's foreign policy in response to this event based on an exhaustive review of unpublished sources from various archives. The purpose of this article is to shed light on the strategies adapted by the military regime to prevent Nicaragua from becoming a center of solidarity with the Chilean opposition overseas.

Key words: sandinista revolution; Chile; Pinochet; Nicaragua; Latin American cold war.

Recibido: 9 de marzo de 2020 Aceptado: 31 de agosto de 2020 Publicado: 23 de diciembre de 2020 


\section{INTRODUCCIÓN}

E ntre 1979 y 1990, el Chile de Pinochet y la Nicaragua sandinista, a pesar de tener posiciones ideológicas antagónicas, mantuvieron relaciones diplomáticas. Fue una situación singular dado que en esos años Chile careció de vínculos con la Unión Soviética y sus aliados europeos, y con Cuba. Además, ambas experiencias finalizaron prácticamente al mismo tiempo, coincidiendo con el momento en que la guerra fría terminaba. A lo largo de la década de los ochenta, estas relaciones experimentaron distintas fases; inicialmente fueron distantes y poco después se deterioraron a causa de la tensión política producida fundamentalmente por las críticas emitidas por dirigentes sandinistas al régimen chileno por la represión política y la falta de libertades. Así, las relaciones estuvieron al borde de la ruptura. También lo cual desembocó en el cierre de la embajada de Chile en Managua en 1985.

Esta experiencia demuestra que las lógicas en el tablero ideológico latinoamericano durante estos años fueron más complejas de lo que pudo parecer en un inicio, porque en las relaciones chileno-nicaragüenses se cruzaron distintas temáticas que de por sí requieren un estudio detallado. Se puede citar a modo de ejemplo las siguientes: La guerra fría global y latinoamericana; las relaciones interamericanas; la solidaridad transnacional; el exilio chileno; y la presencia de combatientes chilenos en la guerra civil nicaragüense, entre otras. Por lo tanto, a pesar de la corta cronología de las relaciones entre estos dos países, las variables que interaccionan en ellas son diversas y significativas.

Respecto a la producción historiográfica, tradicionalmente el impacto de la guerra fría en las relaciones interamericanas se ha centrado en la política exterior estadunidense hacia América Latina o en el apoyo cubano a los procesos revolucionarios de la región. Sin embargo, en las últimas dos décadas, han aparecido varias obras con un enfoque global sobre la guerra fría que permiten comprender con mayor detalle la importancia de Latinoamérica en este escenario. ${ }^{1}$ En cuanto a Latinoamérica, se pueden distinguir dos dimen-

${ }^{1}$ Entre las obras de carácter general resultó una novedad el trabajo de Westad (2007) por abarcar espacios territoriales hasta entonces ignorados por la historiografía occidental. Para la región latinoamericana, véase Brands (2010); Darnton (2014), y Pettinà (2018). También hay algunas recopilaciones de estudios originales como los realizados por Joseph y Spenser (2008); Grandin y Joseph (2010), y Field jr, Krepp y Pettinà (2020). La obra de Marchesi (2019) permite comprender la globalidad de la lucha armada en el continente sudamericano. Para el caso más 
siones directamente relacionadas pero con diferentes protagonistas: los actores estatales y los no estatales. Respecto a la primera, se han realizado varios trabajos académicos sobre las relaciones multilaterales americanas, así como de la interacción entre distintos gobiernos. ${ }^{2}$ Sin embargo, las relaciones bilaterales entre países centroamericanos y sudamericanos en el marco de la guerra fría, por lo general están poco estudiadas, a excepción del caso argentino. ${ }^{3}$ Esta situación tampoco ocurre con México, aspecto sobre el cual existe considerable bibliografía. ${ }^{4}$

Acerca del protagonismo de los actores no estatales, la mayoría de las publicaciones se centran en la solidaridad transnacional con las causas de los derechos humanos o los procesos revolucionarios en numerosos países de la región. Los estudios sobre la solidaridad con las causas revolucionarias centroamericanas incluyen un amplio abanico de temáticas, desde el apoyo a la lucha política, las estrategias propagandísticas utilizadas, hasta la defensa de las víctimas de la represión, por citar algunas. ${ }^{5}$ Asimismo, han ido surgiendo trabajos académicos sobre aspectos más sensibles, como la presencia y el papel que desempeñaron los brigadistas y combatientes extranjeros, generalmente procedentes de organizaciones de izquierda de países latinoamericanos y europeos. ${ }^{6}$

específico de Centroamérica, está disponible la edición de García y Taracena (2017), y Sánchez (2018).

${ }^{2}$ Con esta perspectiva se encuentran los libros de Harmer (2011) y Keller (2015).

${ }^{3}$ Armony (1997) fue el primer académico en investigar el apoyo de la dictadura militar argentina a los gobiernos centroamericanos en la lucha contra la subversión, temática de la que han aparecido algunos trabajos más en los últimos años de la mano de Balerini (2018); Sala (2018); Rostica (2018); Molinari (2018); Lisińska (2018, 2019), y Rostica et al. (2020). Para conocer la posición de Costa Rica frente al golpe de Estado en Chile, véase Molina (2015). No existen trabajos específicos sobre la historia de la política exterior chilena con Centroamérica, aunque Muñoz (1986) dedica algunas páginas a las relaciones del régimen militar con la región. Un extenso trabajo histórico sobre la dimensión internacional de Chile ha sido elaborado por Fermandois (2005), aunque sin referencias a Nicaragua.

${ }^{4}$ Aspectos como la cercanía territorial, la presencia de refugiados centroamericanos en México, así como la importante solidaridad de este país con los procesos revolucionarios centroamericanos, ha resultado en varios estudios detallados como los editados por Vázquez y Campos (2016) y los realizados por Toussaint y Fernández (2019).

${ }^{5}$ Sobre las experiencias de solidaridad, véanse los trabajos de Camacho y Ramírez (2016); Ramírez (2018); Helm (2014a, 2014b); Ágreda (2016); Ágreda y Helm (2016); Van Ommen (2016), y Janssens (2019).

${ }^{6}$ Los principales trabajos son: Cortina (2017); Bravo y Álvarez (2006); Bonnefoy, Pérez y Spotorno (2009); Figueroa (2010); Olivares (2017); Pérez (2013a, 2013b, 2014), y Valdés (2018). En 2016 fue publicada una página web donde se recoge la memoria de los internacionalistas 
Las relaciones políticas entre Nicaragua y Chile empezaron a cobrar cierta importancia durante la segunda mitad década de los sesenta, con la llegada al poder de Eduardo Frei Montalva (1964-1970) y su interés por fortalecer las relaciones con los países de la región, política que también continuó el presidente Salvador Allende (1970-1973). En esos años, varios jóvenes progresistas nicaragüenses viajaron a Chile, tanto para conocer de cerca su proceso político como para realizar estudios universitarios, entre quienes, años más tarde, llegaron a ocupar cargos gubernamentales sumamente importantes dentro del Frente Sandinista de Liberación Nacional (FSLN).

Tras el golpe militar del 11 de septiembre de 1973, las relaciones entre Somoza y Pinochet se fueron intensificando y tuvieron lugar varias visitas de delegaciones políticas. En esa etapa, la embajada de Chile en Managua siguió con detalle la evolución política del país y, de manera simultánea, se ocupó de planear actividades culturales en colaboración con algunas organizaciones dirigidas por chilenos residentes en la capital.

La admiración y el mutuo respeto entre los dos dictadores durante los primeros años fueron la tónica dominante, especialmente porque sus aliados cercanos eran escasos en Occidente a causa de sus prácticas represivas. Sin embargo, según se fue complicando la situación en Nicaragua, las autoridades diplomáticas chilenas empezaron a expresar su preocupación por el destino político del país. Además, antes de la victoria sandinista, el cuerpo diplomático chileno empezó a ser cauteloso con Somoza, especialmente por la falta de garantías democráticas y la corrupción generalizada de su régimen, pero también para lograr así un mayor reconocimiento de la comunidad internacional.

La caída de Somoza en 1979 no generó sorpresa a la Junta Militar chilena, pero la aparición de un nuevo gobierno revolucionario con fuertes vínculos con Cuba y la Unión Soviética empezó a sembrar una gran incertidumbre, fundamentalmente por las consecuencias que esto podría tener dentro del propio territorio nacional. Tras la salida de Somoza, la embajada chilena recibió a varios de sus partidarios en calidad de asilados, y algunos de ellos permanecieron durante largo tiempo. Además, el cuerpo diplomático chileno estableció contactos con los opositores al sandinismo.

La presencia en las filas sandinistas de un número importante de combatientes chilenos durante los últimos meses del régimen somocista, así como

chilenos en Nicaragua. Véase https://nicaraguainternacionalista2016.wordpress.com [Consulta: 23 de febrero de 2020.] 
la llegada de exiliados chilenos para contribuir a la reconstrucción del país, también se entendió como la preparación de una estrategia cuya finalidad sería el derrocamiento del régimen de Pinochet a través de la insurrección armada a mediano o largo plazos. Con el fin de poder seguir de cerca este escenario, la Junta Militar mantuvo abierta su embajada en Managua hasta 1985, fecha en la cual decidió cerrarla por varios motivos como la inexistente voluntad de la contraparte nicaragüense de abrir una delegación en Santiago y las críticas públicas lanzadas contra Pinochet por parte de mandatarios sandinistas.

Con el fin de entender mejor las dinámicas políticas durante los últimos años de la guerra fría latinoamericana, en este artículo se presentan y se analizan los principales aspectos que incidieron en las relaciones chileno-nicaragüenses, donde se incluyen el golpe militar de Pinochet (1973), la revolución sandinista (1979), los primeros años de gobierno del FSLN, y el cierre de la embajada de Chile (1985). De este modo se observa que, a pesar de la distancia geográfica y el pequeño tamaño territorial de Nicaragua, Chile mantuvo el interés por preservar sus vínculos y conocer de cerca su propio proceso político. Con este ejemplo se prueba que la guerra fría latinoamericana puso en el tablero de juego a muchos más actores que Cuba o Estados Unidos, y permite observar cómo tuvieron sus propias lógicas y objetivos en función de sus escenarios nacionales e internacionales.

\section{LAS RELACIONES BILATERALES ENTRE PINOCHET Y SOMOZA (1973-1979)}

El 15 de septiembre de 1973, cuatro días después de producirse el golpe de Estado, la embajada de Chile consultó al régimen nicaragüense por su posición sobre la Junta Militar, la cual reconoció el mismo día. ${ }^{7}$ La embajada de Estados Unidos siguió muy de cerca el desarrollo de las relaciones entre ambos regímenes, tal como se observa en la correspondencia de sus embajadas en Managua y Santiago de Chile con el Departamento de Estado. Así, el 16 de noviembre de 1973, la sede estadunidense en Nicaragua señalaba lo siguiente en relación con el futuro del exembajador de la Unidad Popular en ese país:

7 Oficio ordinario RIA núm. 366/127 de la embajada de Chile en Managua al Ministerio de Relaciones Exteriores, del 17 de septiembre de 1973, fondo Países: Nicaragua. Archivo General Histórico-Ministerio de Relaciones Exteriores (en adelante AGH-MRE, Chile). 
General Eduardo Lema Molina, the Chilean ambassador to Nicaragua appointed by the Allende government, has been removed by the present Chilean government. There was considerable speculation inspired by the former ambassador that in view of his close connections as a general with the military figures presently in charge that he might be retained in his ambassadorial post. As reported in REFTEL, the ambassador had purchased a house in Nicaragua and had requested permission of general Anastasio Somoza to remain here. Based apparently, however, on assurances of some of his military colleagues, the ambassador and his wife have decided to return to Chile although he has informed friends here that he does not have any immediate information regarding a possible future assignment. The ambassador, who had staunchly defended all of the activities of the Allende government, prior to his departure took the position that "it was essential that the communists be removed from the government of Chile."

La comunidad chilena residente en Nicaragua inició una colecta de fondos para enviar a Santiago y contribuir así en la campaña del régimen militar de la llamada reconstrucción del país. ${ }^{9}$ Con el fin de mejorar las relaciones en estos años, el Ministerio de Relaciones Exteriores de Chile apoyó a los candidatos nicaragüenses en los organismos internacionales. Asimismo, se facilitaron los salvoconductos para los asilados que se encontraban en la embajada de Nicaragua en Santiago de Chile pudieran salir del país y para que los nicaragüenses que estaban detenidos en distintos centros, como el Estado Nacional, fueran puestos en libertad..$^{10}$ La reciente llegada a Chile de varios de ellos para continuar sus estudios tras producirse el terremoto de 1972, que se encontraban sin documentación, complicó la situación. ${ }^{11}$ Tras su regreso a Nicaragua,

${ }^{8}$ Cable secreto núm. 1973MANAGU04493_b de la embajada de Estados Unidos en Managua al Departamento de Estado, del 16 de noviembre de 1973. Recuperado de https://wikileaks.org/plusd/cables/1973MANAGU04493_b.html

9 Oficio ordinario doe núm. 38/18 de la embajada de Chile en Managua al Ministerio de Relaciones Exteriores de Chile, fondo Países: Nicaragua. AGH-Mre, Chile.

${ }^{10}$ Entre ellos se destacó Danilo Valle, quien tras la revolución sandinista se convirtió en un alto diplomático. Véase: Cable núm. 211 de la embajada de Chile en Managua al Ministerio de Relaciones Exteriores de Chile, del 19 de octubre de 1979, fondo Países: Nicaragua. AGH-MRE, Chile. En este mismo archivo están disponibles numerosos documentos sobre la detención de ciudadanos nicaragüenses tras el golpe militar.

${ }^{11}$ Cable s. n. del Ministerio de Relaciones Exteriores de Chile a la embajada de Chile en Managua, del 25 de septiembre de 1973, fondo Países: Nicaragua. AGH-Mre, Chile. 
mayoritariamente retomaron las actividades políticas, lo cual hizo que fueran observados con atención por los diplomáticos chilenos. Así, en febrero de 1974 se envió un informe a Santiago con los nombres de catorce de ellos, sugiriendo les fuera prohibida que la entrada a Chile, entre quienes se encontraba la principal figura intelectual del FSLN, Carlos Fonseca Amador. ${ }^{12}$

Ese mismo año, el general de Carabineros y miembro de la Junta Militar, Cesar Mendoza, acudió a Managua en representación del régimen militar a la transición de mando que tuvo lugar el 1 de diciembre de 1974, después de que Somoza fuera reelegido presidente el 1 de septiembre anterior. Con motivo de la visita, el embajador de Chile destacó lo siguiente:

Tanto el discurso de ofrecimiento que hiciera el General señor Mendoza, como el de agradecimiento por el Excelentísimo Señor Presidente de la República fueron muy ovacionados, por su contenido americanista y en que hicieron resaltar la amistad indestructible entre los gobiernos y pueblos de Nicaragua y Chile, porque no sólo ha sido la historia que une a nuestras naciones, sino que a pesar de la enorme distancia, existe conmutación de principios y doctrinas, que los identifica y convierte en Estados hermanos.

Luego, después, el General señor Mendoza hizo entrega al Excelentísimo Señor Presidente de la República, de la réplica de la Espada del Prócer de nuestra Independencia, General don Bernardo O'Higgins, a nombre del Jefe del Estado Chileno, Excelentísimo Señor General de División Augusto Pinochet Ugarte, que agradeció emocionado a su nombre y del pueblo de Nicaragua. ${ }^{15}$

La visita sirvió para fortalecer los vínculos entre ambos regímenes, lo cual se demostró con la intensificación de las actividades sociales del embajador de Chile en Managua, Alfonso Denecken Díaz, especialmente con la cúpula del régimen somocista. Como consecuencia de ello, tanto él, su esposa, y otros altos jerarcas y miembros de la familia de Somoza, fueron secuestrados la noche del 27 de diciembre de 1974 en la casa de José María Castillo Quant, ministro de Agricultura y Ganadería, anfitrión de una fiesta en honor del embajador de Estados Unidos, Turnel Shelton, quien se había retirado an-

${ }^{12}$ Oficio confidencial núm. 55/14 de la embajada de Chile en Managua al Ministerio de Relaciones Exteriores de Chile, del 22 de febrero de 1974, fondo Países: Nicaragua. AGH-Mre, Chile.

${ }_{13}$ Cable reservado núm. 24 de la embajada de Chile en Managua al Ministerio de Relaciones Exteriores de Chile, del 7 de diciembre de 1974, fondo Países: Nicaragua. AGH-Mre, Chile. 
tes del suceso. ${ }^{14}$ Se trató de la primera gran acción del FSLN para conseguir la liberación de 18 de sus miembros, entre quienes se encontraba Daniel Ortega. Además, recibieron 5000000 de dólares por el rescate de los trece últimos rehenes, ${ }^{15} \mathrm{y}$ se puso un avión a su disposición para viajar a Cuba. Con motivo de esta acción, Somoza decretó el Estado de sitio hasta septiembre de 1977. ${ }^{16}$

El incidente con el embajador Denecken no impidió que las relaciones se intensificarán ni frenó la llegada de autoridades chilenas al país. De ese modo, tanto el almirante Ronald McIntyre como el exdiputado Julio Icaza Tijerino visitaron Managua en 1976. Al año siguiente lo hicieron Felipe Rodríguez Serrano, Ramiro Granera Padilla y el general y ex ministro de Defensa Guillermo Noguera Zamora. ${ }^{17}$

La visita del vicecomandante en jefe del ejército de Chile, general de División Carlos Forestier Haensgen, junto con los generales de Brigada Héctor Orozco Sepúlveda, Santiago Sinclair Oyaneder y Luis Joaquín Ramírez Pineda, entre los días 7 y 12 de noviembre, para participar en la XII Conferencia de Ejércitos Americanos, significó un nuevo impulso para la consolidación de los vínculos. Poco después, el ejército de Chile transmitió las siguientes palabras al embajador de su país en Managua: "Es altamente grato, poner en conocimiento de U. S., la excelente opinión que se formó el Sr. Vice Comandante en Jefe del Ejército del Personal antes mencionado por sus especiales deferencias respecto a la Delegación y óptimas conexiones con las autoridades de gobierno del mencionado país, que quedaron en evidencia." ${ }^{18}$

Previamente, el 12 de abril de 1977, el ministro de Relaciones Exteriores de Chile, Patricio Carvajal y el embajador de Nicaragua en Santiago de Chile, Alberto Salinas Muñoz, firmaron un convenio de cooperación cultural. Asimismo, en 1979 se pensó reactivar el Instituto Cultural Nicaragüense-Chi-

${ }^{14}$ Informe reservado núm. 8/1 de la embajada de Chile en Managua al Ministerio de Relaciones Exteriores de Chile, del 3 de enero de 1975, fondo Países: Nicaragua. AGH-Mre, Chile.

${ }^{15}$ Inicialmente fueron secuestradas 35 personas, pero fueron liberados progresivamente, entre ellas, la esposa del embajador Denecken. El propio José María Castillo Quant murió durante el cautiverio. La duración del secuestro fue de 60 horas.

${ }^{16}$ Para conocer con más detalle el deterioro del somocismo y el apoyo del FSLN, véase el trabajo de Sierakowski (2019).

${ }_{17}$ Oficio reservado núm. 189/44 de la embajada de Chile en Managua al Ministerio de Relaciones Exteriores de Chile, del 4 de julio de 1978, fondo Países: Nicaragua. AGH-Mre, Chile.

${ }_{18}$ Oficio reservado núm. 2 del Ministerio de Relaciones Exteriores de Chile a la embajada de Chile en Managua, del 10 de enero de 1978, fondo Países: Nicaragua. AGH-MrE, Chile. 
leno, ${ }^{19}$ integrado mayoritariamente por residentes chilenos en el país, con el objetivo de retomar las actividades culturales y exposiciones que habían quedado paralizadas tras el terremoto de diciembre de 1972. Sin embargo, la inestabilidad política tampoco favorecía su planificación en ese momento.

La buena sintonía quedó confirmada en las palabras enviadas a Santiago por el nuevo embajador de Chile en Nicaragua, Eduardo Gordon Cañas, poco después de su llegada al país, en mayo 1979:

Al día siguiente, a las 16:30 horas, presentaba ante el Primer Mandatario nuestra Embajada para luego saludar yo a uno a uno a los integrantes del Gabinete que se alineaban a un costado y después a los Embajadores y Encargados de Negocios que se alineaban a otro.

Hecho esto iniciamos una amena charla; tal coloquio duró aproximadamente quince minutos, durante los cuales el Presidente Somoza me inquirió con especial afecto por Su Excelencia el Sr. General Pinochet, a la vez que hizo un grato recuerdo de la estadía en Nicaragua, a fines de 1974, para la transición del mando presidencial, del Sr. General Mendoza. Al mismo tiempo, se interesaba por la situación actual de Chile, lo cual expliqué sucintamente, como es obvio por lo apretado del tiempo con que contaba para ello. ${ }^{20}$

El embajador Gordon fue recibido muy rápido tras su llegada a Managua, lo cual no era habitual. Se trató de un gesto especial de cortesía por las simpatías que tenía Somoza con el régimen de Pinochet. En este mismo sentido, Nicaragua respondió favorablemente a casi todas las solicitudes de apoyo a los candidatos chilenos en los organismos internacionales tramitadas desde la embajada de Chile en Managua. ${ }^{21}$ Esta situación era inusual por el aislamiento político en el que se encontraba el régimen chileno.

En esos años, como gesto de amistad por parte de Chile, a finales de 1978 se empezaron a ofrecer becas de formación a los distintos cuerpos de seguridad del somocismo, de lo cual en 1978 da cuenta la embajada de Chile en Managua a través de las siguientes palabras:

19 Oficio ordinario núm. 93/41 de la embajada de Chile en Managua al Ministerio de Relaciones Exteriores de Chile, del 19 de marzo de 1979, fondo Países: Nicaragua. AgH-Mre, Chile.

${ }^{20}$ Informe ordinario núm. 122/54 de la embajada de Chile en Managua al Ministerio de Relaciones Exteriores de Chile, del 18 de mayo de 1979, fondo Países: Nicaragua. AGH-Mre, Chile.

${ }^{21}$ Oficio secreto núm. 8/8 de la embajada de Chile en Managua al Ministerio de Relaciones Exteriores de Chile, del 17 de noviembre de 1978, fondo Países: Nicaragua. AGH-MrE, Chile. 
A fines de año, Carabineros de Chile ofrecía becas para que funcionarios policiales nicaragüenses estudiasen tanto en la Escuela de Carabineros como en su Instituto Superior.

Por otra parte, miembros de la Guardia Nacional concurrían a nuestro país a fin de efectuar cursos de entrenamiento en diversas unidades militares chilenas. $^{22}$

Dada la similitud de ambos regímenes, e igualmente al estimar que la principal amenaza a la seguridad nacional procedía de organizaciones armadas propias del país, la formación estaría centrada sobre todo en combatir la subversión y la insurgencia. Por la misma razón, entre 1976 y 1978, la embajada de Chile en Nicaragua envió numerosos informes en los que se destacaban los enfrentamientos producidos entre la Guardia Nacional y el fSLN.

\section{DEL ASESINATO DE PEDRO JOAQUÍN CHAMORRO A LA CAÍDA DE SOMOZA}

Fue a mediados de la década de los años cincuenta cuando la oposición al somocismo empezó sus primeros pasos, con la presencia de importantes dirigentes que posteriormente formarían las filas del FSLN, como Carlos Fonseca Amador, Tomás Borge o Edén Pastora, por citar algunos. No obstante, y a pesar de algunas acciones armadas de cierta envergadura como el operativo de finales de diciembre de 1974, el régimen no mostró síntomas de debilidad ni preocupación. No fue sino hasta finales de 1977, con la ofensiva de octubre, cuando se inició la coyuntura prerrevolucionaria con la cual el somocismo encontró serias dificultades. Ante el temor de que las acciones de la oposición alcanzaran una envergadura mayor, y en plena escalada de críticas al propio Somoza en los medios de comunicación, aumentaron las accciones represivas. Por este motivo, Pedro Joaquín Chamorro, líder de la Unión Democrática de Liberación (UDEL) y director de La Prensa, el principal diario nicaragüense, fue asesinado el 10 de enero de 1978 por agentes del régimen; lo cual generó tan fuerte indignación que hizo estallar la lucha popular contra la dictadura. Lozano (1989) considera que esta fecha inaugura la primera fase de un total de

22 Oficio secreto núm. 8/8 de la embajada de Chile en Managua al Ministerio de Relaciones Exteriores de Chile, del 17 de noviembre de 1978, fondo Países: Nicaragua. AGH-MrE, Chile. 
seis que conforman la situación revolucionaria en Nicaragua hasta la salida de Somoza del país, y como consecuencia:

[...] se agudizan las contradicciones económicas, políticas y sociales que determinan la profundización y ampliación de la situación revolucionaria, y maduran las condiciones objetivas y subjetivas que garantizan el salto del proceso a la crisis revolucionaria de junio-julio: transformación del movimiento de masas en un "ejército político de la revolución" y consolidación de la dirección político-militar del Frente Sandinista de Liberación Nacional como vanguardia de la lucha revolucionaria (p. 134).

Este momento fue seguido y analizado con detalle por el cuerpo diplomático chileno acreditado en Managua. La reflexión que hizo el embajador de Chile en Managua poco después del atentado coincide en buena medida con la teoría de Lozano:

La muerte de Chamorro, se puede decir con absoluta propiedad, fue el inicio de la agonía del régimen; los disparos que acabaron con la vida física de este inagotable luchador opositor, marcaron también con sangre al Gobierno. La efervescencia popular aumentó súbitamente y el dócil pueblo de antaño, convertido ya en inquieto a finales de 1977, se transformó por completo en un león rabioso a partir de esa fatal muerte. ${ }^{23}$

Entre las principales preocupaciones del cuerpo diplomático chileno en Managua estaba la confirmación de la presencia de combatientes chilenos procedentes de varias organizaciones de izquierda, que hasta fechas recientes se encontraban exiliados en otros países europeos y latinoamericanos, entre ellos Cuba. En sus memorias, Sergio Ramírez (2007) da buena cuenta de ello: "Y acudían voluntarios de todas partes del mundo, como en los años de la Guerra Civil española, a incorporarse al Frente Sur, donde pelearon alemanes, españoles, mexicanos, costarricenses, panameños, colombianos, chilenos, argentinos, dominicanos, uruguayos, venezolanos, cubanos" (p. 250). Ernesto Cardenal (2013) también detalla en sus memorias algunos de sus encuentros con chilenos durante la revolución.

${ }^{23}$ Oficio secreto núm. 8/8 de la embajada de Chile en Managua al Ministerio de Relaciones Exteriores de Chile, del 17 de noviembre de 1978, fondo Países: Nicaragua. AGH-Mre, Chile. 
La toma del Palacio Nacional del 22 de agosto de 1978, perpetrada por un comando del FSLN integrado por 25 guerrilleros liderados por Edén Pastora -también conocido como Comandante Cero-, mientras se celebraba una sesión del congreso nacional, generó un gran impacto en el nivel regional. En esa ocasión se capturaron a alrededor de 3000 rehenes, a quienes se fue liberando progresivamente durante 45 horas hasta que Somoza aceptó las condiciones impuestas por los captores, las cuales consistían en la liberación de numerosos presos políticos, 500000 dólares estadunidenses y dos aviones para salir del país en dirección a Panamá y Venezuela. Entre los rehenes se encontraba el fotógrafo chileno Rafael Alejandro Mella Latorre, quien fue evacuado por acuerdo entre los sandinistas y la Cruz Roja junto a casi 400 personas más. El diario La Tercera de la Hora transcribió con detalle su emotivo testimonio. ${ }^{24}$

Según se fueron intensificando los enfrentamientos, tanto la Guardia Nacional ${ }^{25}$ como los diplomáticos chilenos pudieron constatar la presencia cada vez mayor de combatientes chilenos cerca de la frontera con Costa Rica, en el denominado Frente Sur "Benjamín Zeledón". La embajada chilena remitió detallados informes a Santiago cada vez que conseguía reunir información al respecto, ya fuera a través de publicaciones de prensa o bien de testimonios de informantes. Lo más probable es que mantuvieran dos canales de comunicación, uno más general sobre la situación con el propio Ministerio de Relaciones Exteriores, y otro más secreto con la Central Nacional de Inteligencia (CNI), el principal aparato represivo de la dictadura desde 1977, una vez que fue desarticulada la Dirección Nacional de Inteligencia (DINA), aunque en el archivo no se encuentran informes de esta naturaleza porque podrían haber sido depurados. A modo de ejemplo del primer tipo de correspondencia, se encuentra el siguiente oficio transmitido el 25 de enero de 1979 a Santiago por la embajada de Chile en Managua:

${ }^{24}$ La Tercera de la Hora, 24 de agosto de 1978, p. 29.

${ }^{25}$ El primer chileno caído en combate fue Juan Ernesto Cabezas Torrealba, alias "Hernán”. La referencia militar sobre el retiro de su cadáver se encuentra en: Partes de informes del cuartel general de la Guardia Nacional de San Carlos, río San Juan. Patrulla Bravo de la Guardia Nacional núm. 49/150009, 9 de abril de 1979. Instituto de Historia de Nicaragua y Centroamérica (IHNCA) ASD-067. Archivo del Instituto de Historia de Nicaragua y Centroamérica (en adelante AIHNCA, Nicaragua). 
1. Adjunto al presente oficio remito a US. una serie de recortes de prensa con declaraciones del ciudadano chileno Sr. Haroldo Horta Trikayoti, ${ }^{26}$ elemento integrante del Frente Sandinista de Liberación Nacional, quien fuera capturado recientemente en un enfrentamiento que los guerrilleros sostuvieran con la Guardia Nacional de Nicaragua.

2. El Sr. Horta hace revelaciones sobre la actividad del movimiento extremista en la zona fronteriza de Costa Rica y Nicaragua, como asimismo señala los pormenores de su ingreso al sandinismo.

3. Las únicas referencias a Chile que el citado guerrillero vertió son aquellas cuando manifiesta que las autoridades nicaragüenses le propusieron deportarlo a Chile, pero que eso lo rechaza porque "sería horrible lo que me espera en Chile". ${ }^{27}$

Al mismo tiempo, la hostilidad contra los funcionarios del régimen de Pinochet aumentó según se fue fortaleciendo la oposición a Somoza. Así, en marzo de 1979, el encargado de negocios de Chile, Jorge Garretón Iturra, sufrió un intento de secuestro, hecho que se decidió mantener en secreto. ${ }^{28}$ Por lo cual, unos meses más tarde, la embajada solicitó un segundo escolta, pero

${ }^{26}$ Se refiere al fotógrafo Haroldo Horta Tricallotis, quien una vez en el país decidió sumarse a la guerrilla sandinista. Según Horta, no fue asesinado dado su origen chileno, pues con su detención el régimen de Somoza lo utilizó como evidencia de la injerencia extranjera ante los organismos internacionales. Tras la huida del dictador, fue puesto en libertad y ocupó distintos puestos en el gobierno sandinista en los años sucesivos. Entrevista a Haroldo Horta Tricallotis por vía electrónica con el autor, Madrid, 28 de febrero de 2020. Respecto a su detención, Horta declara lo siguiente: "Con un compañero nos topamos con 30 guardias nacionales. Nos tiraron con un lanzagranadas y la onda expansiva nos arrojó varios metros. Yo cubrí la retirada de mi compañero, pero luego él huyó por la playa. El enemigo abrió un abanico a mi alrededor y me dieron en un pie. Me arrastré de espaldas disparando entre las piernas y me parapeté en un acantilado. Estaba perdido y me lancé a correr por la costa, pero un soldado bajó a la playa y nos enfrentamos en duelo personal. Yo me pegué a la pared del acantilado y él se escondió entre las rocas, pero le di. Y cuando iba a escapar un soldado me gritó desde arriba del acantilado apuntándome. Luego de un violento interrogatorio el jefe decidió matarme y me puso el caño en la sien. Lo vi retirar su cara para evitar salpicarse de sangre, pero antes preguntó cómo me llamaba. Haroldo Horta Tricallotis no es un nombre nica y se dio cuenta de que era chileno. El hombre consideró que podía obtener información de mí y me salvé." Página 12, 10 de mayo de 2015. Recuperado de https://www.pagina12.com.ar/diario/suplementos/turismo/9-3082-2015-05-10. html [Consulta: 21 de febrero de 2020.]

${ }^{27}$ Oficio ordinario núm. 29/8 de la embajada de Chile en Managua al Ministerio de Relaciones Exteriores de Chile, del 25 de enero de 1979, fondo Países: Nicaragua. AGH-MrE, Chile.

${ }^{28}$ Informe secreto núm. 1 de la embajada de Chile en Managua al Ministerio de Relaciones Exteriores de Chile, del 26 de marzo de 1979, fondo Países: Nicaragua; Télex secreto núm. 16 
la petición fue rechaza por Santiago. ${ }^{29}$ Por motivos de seguridad, también se habían distribuido dos revólveres Rossi con una munición de 100 balas. ${ }^{30}$

Cuando la situación se tornó más difícil, el Ministerio de Relaciones Exteriores de Chile también optó por mantener cierta distancia con Somoza. Dadas las altas posibilidades de que acabara siendo derrocado, se estimó preferible mantener los vínculos con quien le sucediera. Principalmente había dos motivos: evitar nuevos adversarios en América Latina, sobre todo que pudieran oponerse de manera importante en los organismos internacionales, y mantener relaciones bilaterales fluidas con la mayor parte de los países posibles, dado que el golpe de Estado de 1973, así como la fuerte represión que se inició después, los había llevado al aislamiento y la marginalidad de la comunidad internacional (Muñoz, 1986).

Antes del deterioro de la situación, en marzo de 1977, Pinochet invitó a Somoza para que visitara Chile, lo cual se iba a materializar en septiembre de ese mismo año, pero el viaje finalmente fue cancelado por motivos de salud del dictador nicaragüense. En junio de 1978, Somoza expresó su deseo de viajar a Chile durante la primera quincena de agosto, antes de visitar Buenos Aires, ya que también tenía una invitación de parte del régimen argentino, ${ }^{31}$ pero se le respondió que la agenda presidencial estaba comprometida para todo lo que quedaba del año, y se le sugirió que viajara al año siguiente, y para evitar problemas, se le indicó que debía avisar con más antelación. ${ }^{32}$ Si bien no se aluden los motivos que estaban detrás de esta decisión, posiblemente el régimen chileno quería ganar tiempo y observar la evolución del desarrollo político nicaragüense antes de recibir al mandatario. A causa de su descrédito internacional no era conveniente recibirlo en Santiago.

Unos meses más tarde se realizó una votación en el seno de la Organización de Estados Americanos (ozA) en la que Chile, por primera ocasión, no se posicionó a favor de Somoza. El propio mandatario expresó su malestar al

del Ministerio de Relaciones Exteriores de Chile a la embajada de Chile en Managua, de marzo de 1979, fondo Países: Nicaragua. AGH-MrE, Chile.

${ }^{29}$ Oficio reservado núm. 267/43 de la embajada de Chile en Managua al Ministerio de Relaciones Exteriores de Chile, del 10 de diciembre de 1979, fondo Países: Nicaragua. AGH-MrE, Chile.

${ }^{30}$ Oficio secreto núm. 3 de la embajada de Chile en Managua al Ministerio de Relaciones Exteriores de Chile, del 21 de febrero de 1980, fondo Países: Nicaragua. AGH-Mre, Chile.

${ }^{31}$ Télex reservado núm. 044 de la embajada de Chile en Managua al Ministerio de Relaciones Exteriores, de junio de 1978, fondo Países: Nicaragua. AGH-MRE, Chile.

32 Télex reservado núm. 024 de Ministerio de Relaciones Exteriores a la embajada de Chile en Managua, de junio de 1978, fondo Países: Nicaragua. AGH-Mre, Chile. 
embajador de Chile por este distanciamiento durante un encuentro que mantuvieron con motivo de la entrega de cuadro al óleo de Bernardo O'Higgins que le obsequiaba el propio Augusto Pinochet:

El Mandatario nicaragüense me manifestó, en tono sumamente dolido, con el sentimiento de quien está profundamente defraudado y agobiado por una tremenda pena, textualmente lo siguiente: "Tenía interés en hablar con Ud. para que le hiciera presente al Sr. General Pinochet que le diera instrucciones a su Delegada ante la OEA a fin de que apoye a Nicaragua en la situación en que se encuentra, en atención a que Nicaragua siempre ha apoyado a Chile e incluso se ha echado de enemigos por sustentar posiciones favorables a su país. Lamentablemente, Chile no nos ha pagado con la misma moneda."

Quiero recalcar ante US. la forma dolida en que el General Somoza pronunció estas palabras, mientras miraba al suelo y aparecía sumamente acongojado, diametralmente opuesto al Somoza altivo y orgulloso, dueño de la situación, que el nicaragüense y el extranjero residente en Nicaragua están acostumbrados a ver.

Esta actitud del Mandatario nicaragüense, demostrada en forma tan contundente en gesto dramático no fingido, pueden dar una pauta de que, en lo sucesivo, Nicaragua no nos apoyará con tanto entusiasmo, como hasta ahora lo ha hecho, ante peticiones a favor de candidaturas chilenas o ante votaciones en contra de proyectos, en organismos regionales o internacionales, que tiendan a lesionar nuestro espíritu nacional. ${ }^{33}$

Con el fin de dar a conocer la situación interna y la posición gubernamental, Somoza envió una delegación diplomática a los distintos países del Cono Sur con el fin de recabar apoyos, la cual aterrizó en Santiago el 23 de noviembre de $1978 .^{34}$

En los siguientes meses, y especialmente a partir de 1979, a causa del aumento de la violencia y la aparición de distintos frentes de combate a lo largo del territorio nacional, la actividad de la embajada de Chile redujo consi-

33 Oficio reservado núm. 295/81 de la embajada de Chile en Managua al Ministerio de Relaciones Exteriores de Chile, del 25 de octubre de 1978, fondo Países: Nicaragua. AGH-MrE, Chile.

34 Télex reservado núm. 090 de la embajada de Chile en Managua al Ministerio de Relaciones Exteriores de Chile, del 21 de noviembre de 1978, fondo Países: Nicaragua. AGH-MrE, Chile. 
derablemente sus actividades, y los encuentros y actividades bilaterales entre ambos países prácticamente desaparecieron. ${ }^{35}$

Durante la ofensiva final que tuvo lugar en junio de 1979, Edén Pastora extendió el rumor de la presencia de mercenarios chilenos dentro de la Guardia Nacional, lo cual fue desmentido por el ministro de Relaciones Exteriores, Hernán Cubillos, el 29 de junio: "Es absolutamente falso que exista ayuda chilena en alguna forma a la Guardia Nacional o al Gobierno actual de Nicaragua. Nosotros somos neutrales en el conflicto y no hay mercenarios chilenos cuando en el conflicto, ni hay noticias sobre un periodista chileno muerto." ${ }^{36}$

Cuando la violencia se hizo incontrolable, 77 chilenos en total, quienes representaban aproximadamente a la mitad de los residentes en Nicaragua, ${ }^{37}$ fueron evacuados del país en dos aviones militares estadunidenses junto con otros residentes extranjeros hacia Panamá, donde fueron recogidos por un avión de Líneas Aéreas Nacionales (LAN). ${ }^{38}$ Para entonces, una mujer chilena murió en su casa a causa de un balazo procedente del exterior, ${ }^{39}$ otro chileno había sido detenido y asesinado por la Guardia Nacional por error, ${ }^{40}$ y un tercero falleció a causa de heridas de bala recibidas mientras transitaba por la calle. ${ }^{41}$

\section{INICIO DE LAS RELACIONES DEL RÉGIMEN PINOCHET CON EL GOBIERNO SANDINISTA}

El 17 de julio de 1979 Anastasio Somoza abandonó el país rumbo a Miami con la esperanza de radicarse en esa ciudad. Sin embargo, el asilo permanente

35 Oficio reservado núm. 68/12 de la embajada de Chile en Managua al Ministerio de Relaciones Exteriores de Chile, del 27 de febrero de 1979, fondo Países: Nicaragua. AGH-Mre, Chile.

36 La Tercera de la Hora, 30 de junio de 1979, p. 5.

37 Télex reservado núm. 076 de la embajada de Chile en Managua al Ministerio de Relaciones Exteriores de Chile, fondo Países: Nicaragua. AgH-Mre, Chile.

38 La Tercera de la Hora, 22 de julio de 1979, p. 2.

39 Informe reservado núm. 175/27 de la embajada de Chile en Managua al Ministerio de Relaciones Exteriores de Chile, del 8 de agosto de 1979, fondo Países: Nicaragua. AGH-MrE, Chile.

${ }^{40}$ Informe reservado núm. 180/29 de la embajada de Chile en Managua al Ministerio de Relaciones Exteriores de Chile, del 14 de agosto de 1979, fondo Países: Nicaragua. AGH-MrE, Chile.

${ }^{41}$ Oficio secreto núm. 1 de la embajada de Chile en Managua al Ministerio de Relaciones Exteriores de Chile, del 31 de enero de 1980, fondo Países: Nicaragua. AGH-MRE, Chile. 
le fue negado y partió hacia Paraguay, donde fue amparado por Stroessner. ${ }^{42}$ Su sucesor fue Francisco Urcuyo Maliaños, ${ }^{43}$ quien permaneció en el poder durante poco más de un día, puesto que su gobierno fue rechazado por la comunidad internacional a favor de la oposición liderada por la junta compuesta por Sergio Ramírez, Violeta Chamorro y Alfonso Robelo, la cual entró en Managua el día 19, junto con el FSLN, para declarar el triunfo de la revolución.

La trascendencia que tuvo la salida de la familia Somoza del poder, la cual ostentaba el poder oficialmente desde $1937,{ }^{44}$ así como la deriva política de Nicaragua, llevó a los diplomáticos chilenos a reflexionar sobre las distintas causas que estaban detrás de estos acontecimientos, enfatizando en la corrupción, el despotismo y el fraude electoral, pero sin mencionar la dimensión represiva o las violaciones de los derechos humanos. Curiosamente, sus conclusiones tenían cierta similitud con el propio proceso vivido en Chile durante la dictadura pinochetista:

Es por todo ello que la Guardia Nacional de Nicaragua carecía en absoluto de una mística militar, $y$, por ende, su entrenamiento castrense era prácticamente nulo. De sus dieciséis mil componentes a la caída del régimen somocista, poco más de dos mil de sus efectivos podían considerarse combatientes. Y con el agravante de que estos últimos respondían a la jefatura de Anastasio Somoza Portocarrero, quien los adiestraba como "guardias de corps" para respaldar sus ya visibles intereses de carácter político. El ya indudable heredero y aspirante a futuro hombre fuerte creaba así su propio ejército dentro del que debería haber sido Ejército Nacional.

\section{Régimen mantenido en base a sistema electoral fraudulento}

No obstante las claras y decidoras primera y segunda características señaladas anteriormente, los Somoza se ufanaban, mostrando con especial orgullo, de

${ }_{42}$ Para conocer con detalle su renuncia, véase: La Prensa, 17 de julio de 2001. Recuperado de https://www.laprensa.com.ni/2001/07/17/politica/764834-ee-uu-oblig-a-somoza-a-dejar-elpoder-el-17-de-julio-de-1979 [Consulta: 29 de agosto de 2020.]

${ }^{43} \mathrm{Su}$ hijo, Mario Lamberto Urcuyo Muñoz, en ese mismo momento residía en Chile cursando segundo año de derecho en la Pontificia Universidad Católica de Chile. Cable reservado núm. 146 de la embajada de Chile en Managua al Ministerio de Relaciones Exteriores de Chile, julio de 1979, fondo Países: Nicaragua. AGH-Mre.

${ }^{44}$ Un trabajo completo sobre la dinastía ha sido realizado por Ferrero Blanco (2010). 
ser los "Mandatarios constitucionales". Si miramos los hechos objetivos, es realmente cierto que siempre asumiendo la Primera Magistratura de la Nación en base a elecciones. Pero no es menos cierto que todo el sistema electoral estaba por completo viciado y que, incluso, en numerosas oportunidades se llegó a pagar gruesas sumas de dinero y otras dádivas a determinadas personas "para que hicieran oposición". ${ }^{45}$

La Junta Militar de Chile reconoció al nuevo gobierno nicaragüense el día 26 de julio de 1979 (Ministerio de Relaciones Exteriores, 1979, p. 36). Con el fin de mantener relaciones cordiales con la Junta de Reconstrucción Nacional que acababa de asumir el poder, el régimen militar envió un avión DC-6 de la Fuerza Aérea con ayuda material compuesta fundamentalmente de ocho toneladas de alimentos, medicinas y ropa, además de tres médicos y un enfermero que se pusieron a disposición de las autoridades sanitarias nicaragüenses. ${ }^{46}$ En el mismo avión se embarcó el director de política bilateral del Ministerio de Relaciones Exteriores, Jaime Lagos, quien se entrevistó con varias autoridades gubernamentales para expresar la voluntad del régimen militar de fortalecer los lazos (Ministerio de Relaciones Exteriores, 1979, p. 36).

En su visita, Lagos quiso conocer la posición de las nuevas autoridades, especialmente del ministro de Relaciones Exteriores, Miguel d'Escoto Brockmann -también por su vinculación con Chile- ${ }^{47}$ y la integrante de la Junta, Violeta Chamorro, para lo cual fue directo en hacer las consultas pertinentes. De ese modo, el 7 de agosto se informó a Santiago lo siguiente:

En las conversaciones que mantuve con el Canciller d'Escoto y con la Sra. Violeta de Chamorro pude apreciar su deseo de continuar manteniendo buenas relaciones con Chile, país al que mucho aprecian particularmente el primero que pasó varios años en nuestro país. Moisés Hassan, otro miembro de la Junta pero de filiación marxista, manifestó a los periodistas chilenos igual intención reiterando uno de los postulados de la Junta nicaragüense de mantener

${ }_{45}$ Oficio secreto núm. 8 de la embajada de Chile en Managua al Ministerio de Relaciones Exteriores de Chile, del 26 de noviembre de 1979, fondo Países: Nicaragua. AGH-Mre, Chile.

${ }^{46}$ Oficio reservado núm. 214/33 de la embajada de Chile en Managua al Ministerio de Relaciones Exteriores de Chile, del 27 de septiembre de 1979, fondo Países: Nicaragua. AGH-Mre, Chile.

47 Entre los años 1963 y 1969 residió en Chile ocupando el puesto de presidente del Instituto Nacional de Acción Poblacional e Investigación (INAPI). 
relaciones con todos los países sin importar su signo ideológico, si respetaban la soberanía interna de Nicaragua.

Aunque el mantenimiento de relaciones con Chile no debe ser algo totalmente del agrado de los sectores del Gobierno marxistas, ya sea por presión de los elementos democráticos o por la conveniencia política de mostrar una actitud pluralista, ellos están dispuestos por el momento a continuar dichas vinculaciones.

La prensa oficial, actualmente controlada exclusivamente por el FSLN, a través de diario "Barricada", ha publicado algunos artículos contrarios al régimen chileno. Ciertos personeros como el Ministro del Interior, Tomás Borge y del Cultura, Ernesto Cardenal también han formulado expresiones críticas hacia el Gobierno chileno. ${ }^{48}$

Entre las nuevas autoridades nicaragüenses también habían sido nombradas otras personas que habían realizado sus estudios universitarios en Chile, como el viceministro de Relaciones Exteriores, Álvaro Ramírez González, y el director adjunto de protocolo, Danilo Valle, quien poco después viajó a Chile para explicar el motivo del cierre de la embajada nicaragüense en Santiago. ${ }^{49}$ Asimismo, entre quienes habían realizado sus estudios universitarios en Chile se encontraban Jaime Wheelock Román, ministro de Agricultura y uno de los nueve comandantes de la dirección del FSLN, así como su hermano Ricardo Wheelock Román, quien fue nombrado embajador en la Unión Soviética y más tarde en Bulgaria, y esposo de la ciudadana chilena Mónica Zalaquett Daher. ${ }^{50}$

Dado el vínculo con Chile del ministro d'Escoto, desde Santiago se barajó la posibilidad de invitarlo a regresar al país, pero ante el aumento de las

${ }^{48}$ Informe confidencial núm. 2596 del director de política bilateral al ministro de Relaciones Exteriores de Chile, del 7 de agosto de 1979, fondo Países: Nicaragua. AGH-Mre, Chile.

${ }^{49}$ El último embajador nicaragüense en Santiago fue William Barquero Montiel. Su antecesor, Alberto Salinas Muñoz (1978) recibió la orden al mérito de Chile en el grado de Gran Cruz. A partir de entonces, la embajada de Nicaragua en Buenos Aires fue concurrente en Chile.

${ }^{50}$ Jaime Wheelock estuvo casado durante varios años con la hermana de Mónica, Patricia Zalaquett Daher. Los diplomáticos chilenos hicieron un seguimiento especial de los sandinistas casados con mujeres chilenas. Télex reservado núm. 058 de la embajada de Chile en Managua al Ministerio de Relaciones Exteriores de Chile, del 3 de septiembre de 1984, fondo Países: Nicaragua. AGH-MRE, Chile. 
críticas gubernamentales a Pinochet, se desestimó la invitación. ${ }^{51}$ Las declaraciones del alto funcionario nicaragüense siempre fueron muy cordiales con Chile, lo cual agradó al régimen pinochetista, pero con el paso del tiempo se percataron de que no tenían la más mínima trascendencia en el fortalecimiento de los vínculos. Con estas palabras sacaron su conclusión:

Nada sacamos con que el Canciller o el Viceministro del Exterior nos acogen con palabras halagadoras y pletóricas de buena voluntad; siempre encontramos que se nos escucha en tono amable y bondadoso. Pero de ahí a que se concrete lo que se pide, que nunca es nada del otro mundo, es difícil, por no decir imposible. Porque todo está dictado "desde arriba", desde la cúpula del FSLN, donde prima la ideología y la pleitesía a Cuba. Y esto tiene que quedar bien claro a nuestro Ministerio. Las relaciones entre Chile y Nicaragua, así como las de este último país con cualquier otro, quedarán subordinadas a los dictados cubanos. ${ }^{52}$

Se visibilizaba así que las relaciones entre Chile y Nicaragua empezaban a ser cada vez más complejas. Por este motivo, además de la falta de interés del gobierno sandinista de tener una representación en Santiago, el Ministerio de Relaciones Exteriores de Chile decidió rebajar la máxima representación diplomática, razón por la cual el embajador, Eduardo Gordon Cañas, quien había asumido el puesto el año anterior como relevo de Manuel Stagno Migone ${ }^{53}$ regresó a Chile en noviembre de 1980. También se consideró la posibilidad de romper relaciones diplomáticas, pero los funcionarios del régimen pinochetista sabían el valor que tenía el hecho de mantenerse presentes en Nicaragua:

En el segundo semestre de 1980 las relaciones chileno-nicaragüenses llegaron a su punto histórico más bajo. En septiembre, y luego de un nuevo incidente ocasionado por injurias a S.E. el presidente de la República proferidas por el Ministro de Defensa, y miembro de la Dirección Nacional del Frente Sandinista, Comandante de la Revolución Humberto Ortega, se resolvió el retiro

${ }^{51}$ Oficio secreto núm. 19 de la embajada de Chile en Managua al Ministerio de Relaciones Exteriores de Chile, del 15 de diciembre de 1980, fondo Países: Nicaragua. AGH-Mre, Chile.

${ }_{52}$ Oficio reservado núm. 1/1 de la embajada de Chile en Managua al Ministerio de Relaciones Exteriores de Chile, del 2 de enero de 1980, fondo Países: Nicaragua. AGH-Mre, Chile.

${ }^{53}$ General de Carabineros, quien se desempeñó como embajador de Chile en Managua entre 1976 y 1979 . 
del Embajador Eduardo Gordon. Esta medida constituyó un paso adicional en el procedimiento escalonado, reflexivo y sereno que nuestro Gobierno ha empleado para responder a los actos inamistosos del régimen sandinista.

La "Semana de solidaridad con el pueblo de Chile" organizada aquí por un organismo de fachada del FSLN mostró por su parte los más altos niveles conocidos de virulencia en la actividad antichilena. [...]

Por último, estimamos que en el caso límite de una ruptura de relaciones diplomáticas, es conveniente mantener este valioso puesto de observación -al menos- en la forma de una oficina consular..$^{54}$

A partir de entonces y hasta el cierre de la delegación chilena, la máxima autoridad fue el encargado de negocios, siendo Alfredo Labbé Villa el primero en ocupar el puesto (1981-1982), y Eduardo Vega Bezanilla (1982-1984).

El intercambio de visitas entre ambos países no fue intenso. Al inicio fueron escasas, aunque aumentaron levemente entre los años 1982 y 1983. Por la parte chilena se destacaría la llegada a Managua del director de Relaciones Económicas Multilaterales del Ministerio de Relaciones Exteriores de Chile para participar en la Primera Reunión Ordinaria del Comité de Acción del Sistema Económico Latinoamericano y del Caribe (SELA) para la Reconstrucción de Nicaragua, celebrada en febrero de 1980, y la visita del subsecretario de pesca, Roberto Verdugo Gómez, para participar en la I Conferencia Internacional de Ministro de Pesca y en la VII Reunión Ordinaria del Comité de Acción de Productos del Mar y Agua Dulce, ambas a finales de octubre de 1984. Por la parte nicaragüense, se encuentra el viaje realizado por el Monseñor Miguel Obando y Brazo, arzobispo de Managua y presidente de la Conferencia Episcopal, además de un abierto opositor al FSLN, para formar parte de una reunión del Consejo Episcopal Latinoamericano (CELAM) en Santiago, celebrada en marzo de 1981, y la llegada en 1983 del viceministro de Agricultura, Manuel Coronel Kautz, para estudiar la posibilidad de establecer contacto con el sector agropecuario chileno, por un lado, y barajar la posibilidad de abrir una misión diplomática, por el otro, lo cual generaba opiniones encontradas en el régimen

${ }^{54}$ Oficio secreto núm. 19 de la embajada de Chile en Managua al Ministerio de Relaciones Exteriores de Chile, del 15 de diciembre de 1980, fondo Países: Nicaragua. AGH-MrE, Chile. 
chileno. ${ }^{55}$ Sin embargo, nada llegó a materializarse, por lo que posiblemente se trató de un viaje para conocer de cerca la realidad política del país. ${ }^{56}$

El malestar de la Junta Militar chilena aumentó en la medida que altos dirigentes chilenos en el exilio comenzaban a llegar a Managua para participar en distintos encuentros en solidaridad con la revolución sandinista y en conferencias de corte político, siendo recibidos con honores y una gran atención; entre ellos se encontraron Jacques Cholchol, Clodomiro Almeyda, Andrés Pascal Allende, Anselmo Sule, Hortensia Bussi, Volodia Teitelboim y Luis Maira, por citar algunos. ${ }^{57}$

Otro de los primeros incidentes que se produjo entre la embajada y las nuevas autoridades fue la detención de residentes chilenos por estar supuestamente vinculados con el somocismo. Si bien finalmente fueron liberados ante la falta de pruebas (Ministerio de Relaciones Exteriores, 1980, p. 52), quedaba constancia que quienes residían en el país antes del inicio de las hostilidades no tenían simpatía por el sandinismo. Sin embargo, su presencia fue cada vez más marginal ante la llegada de un número cada vez mayor de chilenos exiliados en otros países de la región y de Europa.

A causa de un error técnico, durante los primeros meses de 1980 varios télex secretos enviados desde la embajada de Nicaragua en Washington a Sergio Ramírez fueron recibidos en la delegación chilena en Managua. Además de compartir el contenido de los documentos, se solicitaron instrucciones a Santiago sobre cómo proceder, si mantener el silencio para recibir esa in-

${ }_{55}$ La posición de los funcionarios del régimen chileno respecto a la apertura de una delegación nicaragüense en Santiago era dispar. Por un lado, consideraban que era un requisito fundamental para que las relaciones bilaterales se mantuvieran equitativas, pero, por otro, también estaban temerosos. Según el encargado de negocios de Chile en Managua: "el único elemento verdaderamente nuevo en las relaciones bilaterales es la intención de Nicaragua de abrir una Embajada en Santiago, la cual, como he señalado a US. en comunicaciones anteriores, no responde a un deseo sincero de mejorar las relaciones con nuestro Gobierno, sino al contrario, de establecer una cabeza de puente en el país que sirva para ayudar a los elementos de la extrema izquierda chilena en la actual coyuntura política". Oficio secreto núm. 15/83 de la embajada de Chile en Managua al Ministerio de Relaciones Exteriores de Chile, del 20 de octubre de 1983, fondo Países: Nicaragua. AGH-MRE, Chile.

${ }^{56}$ Oficio reservado núm. 62/84 de la embajada de Chile en Managua al Ministerio de Relaciones Exteriores de Chile, del 8 de junio de 1984, fondo Países: Nicaragua. AGH-MrE, Chile.

${ }^{57}$ En numerosos informes guardados en el fondo de Nicaragua del AGH-MRE se observa que los diplomáticos chilenos acreditados en Nicaragua durante esta etapa seguían detalladamente las actividades y las declaraciones de los dirigentes de izquierda que llegaban al país para participar en actos políticos de apoyo a la revolución y de denuncia al régimen de Pinochet. 
formación privilegiada o bien notificar a las respectivas autoridades. ${ }^{58}$ Desde Santiago, con el fin de evitar un posible incidente, se dio la orden de notificar al Ministerio de Relaciones Exteriores de Nicaragua en el caso de que volviera a llegar un nuevo mensaje. ${ }^{59}$

El 17 de septiembre de 1980, Somoza fue asesinado, junto su chófer y un asesor, en la ciudad de Asunción por un comando de guerrilleros argentinos del Ejército Revolucionario del Pueblo (ERP) liderados por Enrique Gorriarán Merlo y Hugo Irurzún, episodio conocido como "Operación Reptíl". Anteriormente ambos habían combatido en el Frente Sur "Benjamín Zeledón", destacándose por su determinación en los combates contra la Guardia Nacional, motivo por el cual establecieron estrechos vínculos con la dirigencia sandinista. El 30 de octubre de 1980, el mismo fotógrafo chileno que había sido rehén durante la toma del Palacio Nacional de Nicaragua de agosto de 1978, Rafael Alejandro Mella Latorre, en ese momento residente en Asunción, fue detenido por la policía paraguaya bajo la acusación de haber participado en el atentado, ${ }^{60}$ lo cual generó inquietud en el régimen pinochetista al considerar que los grupos de oposición estaban empezando a realizar operativos en países latinoamericanos con gran éxito, aunque también tenían ciertas dudas sobre la profesionalidad de las fuerzas de seguridad paraguayas. ${ }^{61}$

${ }^{58}$ Oficio reservado núm. 98/59 de la embajada de Chile en Managua al Ministerio de Relaciones Exteriores de Chile, del 8 de mayo de 1980, fondo Países: Nicaragua. AGH-Mre, Chile.

59 Télex reservado núm. 032 del Ministerio de Relaciones Exteriores de Chile a la embajada de Chile en Managua, de mayo de 1980, fondo Países: Nicaragua. AgH-Mre, Chile.

${ }^{60}$ Rafael Mella Latorre permaneció preso en Paraguay hasta 1989, días después del derrocamiento de Stroessner, que fue expulsado a Chile. Durante su cautiverio fue sometido a torturas físicas y psicológicas. ABC en el Este, 18 de agosto de 2017. Recuperado de https://www. abc.com.py/edicion-impresa/locales/mella-latorre-declaro-como-victima-1623504.html [Consulta: 24 de febrero de 2020.] El periodista Julián Mandriotti (2003) sostiene que el asesinato de Somoza se debió exclusivamente a motivos personales, y fue perpetrado por Mella Latorre, quien según él se encontraba en Asunción trabajando para los servicios secretos del régimen de Pinochet como agente doble, por encargo de Humberto Domínguez Dibb, empresario y yerno de Stroessner, a cambio de 400000 dólares. Parte de esta información fue detalladamente publicada por la prensa chilena durante 1981 y puntualmente en los años siguientes. El día 23 de enero de 1981 (p. 1) el diario El Mercurio dedicó un extenso artículo a Mella Latorre.

${ }^{61}$ Oficio secreto núm. 1 de la embajada de Chile en Asunción al Ministerio de Relaciones Exteriores de Chile, 26 de febrero de 1981, fondo Países: Paraguay. AGH-Mre, Chile. 


\section{LOS ASILADOS Y HUÉSPEDES DE LA EMBAJADA DE CHILE}

La velocidad con la que se derrumbó la dictadura somocista, así como la dificultad de movilidad terrestre dada la existencia de distintos frentes de guerra a lo largo y ancho del país, dificultó la estampida de los enemigos del sandinismo; por lo cual las embajadas principalmente de los países latinoamericanos se llenaron rápidamente de asilados políticos. En total, para comienzos de agosto de 1979 llegaron a sumar alrededor de 1900 casos, aunque 300 de ellos se resolvieron fácilmente porque eran mayoritariamente mujeres y niños. ${ }^{62}$ Sobre todo se trató de antiguos integrantes de la Guardia Nacional y sus familiares, además de funcionarios del régimen, que estaban temerosos de ser sometidos a juicio por los atropellos cometidos durante el régimen de Somoza. Después del golpe de Estado del 11 de septiembre de 1973 en Chile, fue la experiencia política que más asilados generó en toda América Latina. ${ }^{63}$ En esa ocasión, las autoridades chilenas no eran quienes perseguían y entorpecían la labor de los diplomáticos extranjeros, sino que ellos mismos se vieron expuestos, por primera vez, en la situación contraria, siendo ahora, seis años después del derrocamiento de Salvador Allende, quienes criticaron y denunciaron la dificultades generadas por dicha situación, especialmente por la demora en conseguir los salvoconductos necesarios para que los exsomocistas pudieran abandonar su recinto diplomático.

A lo largo del mes de julio entraron los primeros siete asilados en la embajada chilena ${ }^{64}$ aunque uno de ellos decidió abandonar el recinto voluntariamente días más tarde. ${ }^{65}$ En poco tiempo recibieron los salvoconductos correspondientes para ir a Estados Unidos, Guatemala y Honduras. ${ }^{66} \mathrm{El} 21$ de febrero de 1980 llegaron a Chile cuatro asilados más que habían entrado en la embajada posteriormente (Ministerio de Relaciones Exteriores, 1980, p. 52). El caso más

${ }^{62}$ Oficio reservado núm. 214/33 de la embajada de Chile en Managua al Ministerio de Relaciones Exteriores de Chile, del 27 de septiembre de 1979, fondo Países: Nicaragua. AGH-Mre, Chile.

${ }^{63}$ Para conocer la situación vivida en los recintos diplomáticos de Santiago de Chile tras el golpe militar, véase Camacho Padilla (2006).

${ }_{64}$ Oficio ordinario núm. 155/61 de la embajada de Chile en Managua al Ministerio de Relaciones Exteriores de Chile, del 2 de agosto de 1979, fondo Países: Nicaragua. AGH-Mre, Chile.

${ }^{65}$ Oficio ordinario núm. 171/66 de la embajada de Chile en Managua al Ministerio de Relaciones Exteriores de Chile, del 9 de agosto de 1979, fondo Países: Nicaragua. AGH-Mre, Chile.

${ }^{66}$ Nota verbal núm. 69 de la embajada de Chile en Managua al Ministro de Relaciones Exteriores de Nicaragua, del 1 de agosto de 1979, fondo Países: Nicaragua. AGH-MRE, Chile. 
complicado para la obtención de los respectivos permisos por su responsabilidad en las tareas represivas somocistas ocurrió con el excapitán de la Guardia Nacional Alberto José Baca Reyes, quien había entrado en la embajada el 22 de julio de 1979. Finalmente, partió hacia Chile el 20 de noviembre de 1983 después de largas negociaciones (Ministerio de Relaciones Exteriores, 1983, p. 41).

Asimismo, la embajada de Chile se convirtió en un importante centro social de los grupos de oposición al sandinismo. Dos años después del triunfo de la revolución, se remitió el siguiente informe a Santiago:

Paralelamente, y dentro de las limitaciones presupuestarias, se ha desplegado una actividad social lo más intensa posible para ampliar las fuentes de información de la Embajada y difundir la realidad nacional (8 recepciones con un total de asistencia cercano a las 800 personas durante lo corrido de 1981). La Lista Social de la Misión incluye nombres de aproximadamente 150 personalidades políticas, religiosas, del sector económico privado, de la prensa y culturales, entre ellos altos dirigentes de las fuerzas democráticas. A dicha Lista debe agregarse el Cuerpo Diplomático y las autoridades de Gobierno. ${ }^{67}$

Existen abundantes informes respecto de las recepciones organizadas por los diplomáticos chilenos, en las cuales rinden cuentas del número de asistentes y los cargos que representaban, además de los temas de conversación, por lo general favorables al régimen de Pinochet y contrarios al gobierno sandinista. Entre ellos, solían acudir los embajadores de Estados Unidos, Argentina, España, Ecuador, Italia, Francia, Alemania Federal, Perú, Colombia, Guatemala, Honduras, El Salvador, y los encargados de negocios y consejeros de las embajadas de Venezuela, España y Japón, entre otros. Los nicaragüenses que acudían regularmente eran el nuncio apostólico, Emilio Álvarez Montalván (alto mandatario del Partido Conservador Demócrata), Ismael Reyes Icabalceta (presidente de la Cruz Roja y de la Cámara de Industrias de Nicaragua), Reynaldo Hernández (presidente de la Cámara de Comercio), Jaime Montealegre (dirigente del Movimiento Democrático Nicaragüense [MDN]), Mario Alfaro (jefe de redacción del diario La Prensa), y Álvaro Jerez (secretario político del MDN).$^{68}$

${ }^{67}$ Oficio secreto C-001/001 de la embajada de Chile en Nicaragua al Embajador de Chile en Panamá, del 10 de agosto de 1981, fondo Países: Nicaragua. AGH-Mre, Chile.

${ }^{68}$ Oficio ordinario núm. 46/15 de la embajada de Chile en Managua al Ministerio de Relaciones Exteriores de Chile, del 15 de abril de 1981, fondo Países: Nicaragua; oficio ordinario 
Con esta estrategia se lograron fortalecer los vínculos con la disidencia al sandinismo, tales como la Comisión Permanente de Derechos Humanos en Nicaragua ${ }^{69}$ y los partidos que integraban la Coordinadora Democrática Nicaragüense. El 3 de octubre de 1984, el encargado de negocios en Managua señalaba: "se ha llegado a un muy buen nivel con los dirigentes del Partido Conservador y del Partido Liberal Constitucionalista, y a un grado de receptividad satisfactorio con los Partidos Liberal Independiente, Social Cristiano, Social Demócrata y Conservador Demócrata".70

Estas organizaciones remitían a la embajada chilena todas sus publicaciones e informes críticos al gobierno, tales como declaraciones políticas y documentos sobre la situación de los derechos humanos, especialmente aquellos que guardaban relación con los indígenas Miskitos y las condiciones carcelarias en las que se encontraban ex miembros de la Guardia Nacional. También se enviaban a Santiago detallados informes sobre la ofensiva de la Contra, además de ejemplares del semanario Guazapa,${ }^{71}$ impreso en Managua por la Resistencia Nacional, uno de los grupos integrantes del Frente Farabundo Martí de Liberación Nacional (FMLN) de El Salvador.

\section{CAUSAS DEL DETERIORO DE LAS RELACIONES BILATERALES Y CIERRE DE LA EMBAJADA DE CHILE}

Tan pronto se fue estabilizando la situación en Nicaragua, las declaraciones y acciones críticas contra el régimen de Pinochet fueron aumentando, tanto en actividades políticas como en la emisión de programas de radio y de documentales en televisión. La embajada de Chile siguió todo aquello que pudiera entenderse como una posición hostil al régimen de Pinochet. En septiembre

núm. 67/18 de la embajada de Chile en Managua al Ministerio de Relaciones Exteriores de Chile, del 15 de mayo de 1981, fondo Países: Nicaragua. AGH-Mre, Chile.

${ }^{69}$ Oficio reservado núm. 96/57 de la embajada de Chile en Managua al Ministerio de Relaciones Exteriores de Chile, del 7 de mayo de 1980, fondo Países: Nicaragua. AGH-Mre, Chile.

${ }^{70}$ Oficio secreto núm. 17/84 de la embajada de Chile en Managua al Ministerio de Relaciones Exteriores de Chile, del 3 de octubre de 1984, fondo Países: Nicaragua. AGH-Mre, Chile.

${ }^{71}$ Según Cortina Orero (2016): Guazapa se orientó a destinatarios internacionales, convirtiéndose en un órgano que circuló principalmente entre Nicaragua, México y Costa Rica, y que se enfocó en alimentar a la solidaridad, el trabajo de la Resistencia Nacional (RN) sobre el campo intelectual y dar orientación a los números de simpatizantes (p. 426). 
de 1980 se celebró la semana de la solidaridad con Chile, a la cual llegaron varios dirigentes de la oposición en el exilio. Como parte del programa, en las salas de cine se exhibió el documental "La Batalla de Chile", de Patricio Guzmán, lo cual alarmó a los diplomáticos chilenos $;^{72}$ y para evitar la proyección, el Ministerio de Relaciones Exteriores de Chile recordó al gobierno de Nicaragua un acuerdo firmado entre ambos Estados el 14 de julio de 1938, en el que se comprometían "a no permitir la proyección -dentro de sus respectivos territorios- de películas que pudiesen ser denigradoras para el otro país". ${ }^{73}$

Además de las declaraciones críticas contra Pinochet, Nicaragua empezó a recibir a bastantes chilenos procedentes del exterior, quienes llegaron a ocupar cargos relevantes en la administración pública y en el propio seno del ejército sandinista, incluso destacándose en los combates con la Contra. Al respecto, en junio de 1981, la embajada chilena remitió el siguiente informe a Santiago:

\section{Asilados chilenos:}

Numerosos exiliados políticos, exfuncionarios del Gobierno de la UP. y miembros de los partidos que la integraron, como también militantes del MIR permanecen en Nicaragua, colaborando estrechamente con el régimen revolucionario, a veces en puestos de gran importancia (Ejército, Policía, Dirección General de Seguridad del Estado).

Es difícil determinar su número, pero no debe ser inferior a mil. Su actividad se enmarca generalmente en tareas de Gobierno. El aparato de propaganda sandinista recoge periódicamente contribuciones de los "internacionalistas" chilenos. ${ }^{74}$

Sobre todo se trató de jóvenes militantes del Partido Comunista Chileno o del Movimiento de Izquierda Revolucionaria que habían recibido formación militar en países de Europa del Este y Cuba. Uno de los más destacados fue el capitán Raúl Vergara Meneses, por coordinar la Fuerza Aérea Sandinista y ser el responsable de la segunda jefatura en la parte operativa (Pérez Silva, 2013a, p. 156).

${ }^{72}$ Télex reservado núm. 211 de la embajada de Chile en Managua al Ministerio de Relaciones Exteriores, del 4 de septiembre de 1980, fondo Países: Nicaragua. AGH-MrE, Chile.

${ }^{73}$ Oficio reservado núm. 16 del Ministerio de Relaciones Exteriores de Chile a la embajada de Chile en Managua, del 6 de diciembre de 1979, fondo Países: Nicaragua. AGH-Mre, Chile.

${ }^{74}$ Oficio reservado núm. 96/ 27 de la embajada de Chile en Managua al Ministerio de Relaciones Exteriores de Chile, s. f. (1981), fondo Países: Nicaragua. AGH-Mre, Chile. 
Varios de los chilenos que decidieron establecerse en Nicaragua debieron dirigirse al consulado para resolver distintos trámites administrativos. Sus solicitudes fueron revisadas con lupa, y desde Santiago se dio la orden de “otorgar o revalidad pasaporte con letra ' $L$ ' en forma inmediata a toda persona que figure en el Listado Nacional o en sus circulares complementarias". ${ }^{75} \mathrm{~A}$ pesar de esta medida, varios de ellos lograron entrar clandestinamente a Chile con el objetivo de derrocar a la dictadura, generalmente exmiembros de la juventud del Partido Comunista Chileno y ahora cuadros militares del Frente Patriótico Manuel Rodríguez. Posteriormente, algunos fueron asesinados, entre quienes estaban Raúl Pellegrín, José Valenzuela Levi, Roberto Nordenflycht y Moisés Marilao. ${ }^{76}$ También hubo casos de chilenos residentes que, por distintos motivos, solicitaron en el consulado en Managua regresar a Chile. En una ocasión, un excombatiente chileno del FSLN llamado José Orlando González García entregó voluntariamente información sobre la participación de otros compatriotas en la organización y en el nuevo gobierno nicaragüense, a cambio del permiso de regreso. ${ }^{77}$

Un nuevo incidente se produjo cuando el gobierno sandinista decidió nombrar Salvador Allende a una de las avenidas más importantes de Managua. Así, la embajada chilena trasmitió una nota al Ministerio de Relaciones Exteriores expresando su malestar por el incidente, a la cual respondieron sarcásticamente con las siguientes palabras:

Realmente estamos profundamente extrañados por los argumentos empleados por usted al manifestar inconformidad y sorpresa por la nominación del paseo como "paseo Salvador Allende", un ex-pdte. de vuestra patria y cuya figura traspasó las fronteras chilenas hasta convertirse en un internacionalista, representante de las causas justas de nuestra América Latina. Salvador Allende un hombre electo por su pueblo que luchó y murió por los oprimidos de Chile está presente en nuestra revolución. ${ }^{78}$

${ }^{75}$ La letra "L" se colocaba en los pasaportes de los exiliados que tenían prohibida la entrada a Chile. Oficio reservado núm. 2 del Ministerio de Relaciones Exteriores de Chile a la embajada de Chile en Managua, del 5 de junio de 1981, fondo Países: Nicaragua. Agh-Mre, Chile.

${ }^{76}$ Para conocer con más detalle cada uno de los casos, véase Pérez Silva (2013b).

${ }_{77}$ Oficio secreto núm.7 de la embajada de Chile en Managua al Ministerio de Relaciones Exteriores de Chile, 17 de marzo de 1980, fondo países: Nicaragua. AGH-Mre, Chile.

${ }_{78}$ Télex reservado núm. 226 de la embajada de Chile en Managua al Ministerio de Relaciones Exteriores de Chile, del 22 de septiembre de 1980, fondo Países: Nicaragua. AGH-Mre, Chile. 
Ante los numerosos incidentes similares que se siguieron sucediendo en los años posteriores, resultaba evidente que la embajada no lograba fortalecer los vínculos bilaterales. No obstante, su verdadera función, tal como aparece en el siguiente informe redactado años más tarde, fue el siguiente:

3.1. Tradicionalmente esta Misión ha sido concebida como un puesto de observación y análisis. Esta Misión continuará cumpliendo dicho propósito, preocupándose especialmente de observar la penetración de Cuba y la Unión Soviética y sus satélites; el grado de armamentismo del Gobierno nicaragüense; la capacitación de extranjeros en la lucha guerrillera (ej. Chilenos); el grado de infiltración nicaragüense en los demás países centroamericanos y la consiguiente exportación de su revolución; el envío de armas a El Salvador; la presencia de militares y asesores extranjeros; la actividad que desarrollen chilenos exiliados a nivel de gobierno, etcétera. ${ }^{79}$

Después del terremoto que asoló a Chile el 3 de marzo de 1985, el gobierno sandinista hizo una donación de 10000 dólares, a través de la Cruz Roja de su país, para hacer frente a los daños causados (Ministerio de Relaciones Exteriores, 1985, p. 37). Se trató de un gesto inesperado por el régimen militar chileno y que "considerando dramática situación económica Nicaragua, es un gesto de alta significación" ${ }^{80}$ Sin embargo, no sirvió para compensar el constante malestar en el que se encontraban por la posición hostil hacia el régimen.

Dadas las constantes declaraciones en contra de la Junta Militar de Chile, el 30 de septiembre de 1985 se decidió cerrar la embajada en Managua, aludiendo a razones presupuestarias. ${ }^{81}$ A partir de ese momento, sería la representación de Chile en San José de Costa Rica la concurrente ante Nicaragua. El último encargado de negocios, Pedro Uriarte Peña, fue quien informó a las autoridades sandinistas de la decisión. Durante la reunión que mantuvo con el viceministro de Relaciones Exteriores de Nicaragua, José León Talavera, entre los distintos puntos, le señaló lo siguiente:

${ }^{79}$ Oficio secreto núm. 16/84 de la embajada de Chile en Managua al Ministerio de Relaciones Exteriores de Chile, del 3 de octubre de 1984, fondo Países: Nicaragua. AGH-MrE, Chile.

${ }^{80}$ Télex reservado núm. 032 de la embajada de Chile en Managua al Ministerio de Relaciones Exteriores, del 12 de marzo de 1985, fondo Países: Nicaragua. AGH-MRE, Chile.

${ }^{81}$ Oficio reservado núm. 225/85 de la embajada de Chile en Managua al Ministerio de Relaciones Exteriores de Chile, del 26 de septiembre de 1985, fondo Países: AGH-MrE, Chile. 
5. Le expresé con absoluta franqueza, que los "pequeños inconvenientes" que él aludía no eran pequeños sino grandes y que habían motivado enérgicas protestas de nuestro gobierno las que nunca habían sido contestadas. Le hice completo desarrollo relaciones ambos países últimos seis años y particularmente mi periodo, actitud permanentemente hostil en tema derechos humanos, e incluso actitud negativa en candidaturas chilenas, votación en conferencia OIT en impugnación poderes trabajadores chilenos, etc. ${ }^{82}$

A pesar del cierre de la embajada chilena en Managua en 1985, las relaciones bilaterales no fueron interrumpidas, aunque pasaron a un plano en el cual eran prácticamente inexistentes. La ausencia de funcionarios del régimen militar tranquilizó a la mayoría de los residentes chilenos en el país centroamericano, principalmente porque dejaron de sentirse observados. De igual forma, el gobierno sandinista entendió que tenía mayor margen de acción contra Pinochet al no tener a sus agentes en el país. Un año más tarde, el gobierno sandinista colaboró en el operativo de envío de armas a Chile acordado entre Cuba y el Partido Comunista Chileno, ejecutado por el Frente $\mathrm{Pa}$ triótico Manuel Rodríguez (FPMR), mediante un operativo de desembarco en la localidad costera de Carrizal Bajo, en la región de Atacama. La operación fue descubierta a inicios del mes de agosto por las fuerzas de seguridad chilenas, aunque para entonces, la mitad del cargamento ya había sido entregado a sus destinatarios. ${ }^{83}$

El régimen de Pinochet, por su parte, también consideró durante estos años la posibilidad de apoyar militarmente a la Contra con la venta de $48 \mathrm{mi}-$ siles, además de la formación técnica para su manejo, para lo cual contó con la mediación de Oliver North, quien estaba a cargo de la operación Irán-Contra. Sin embargo, y a pesar de todas las gestiones realizadas, no llegó a concretarse por la negativa de las autoridades responsables de la Casa Blanca (Kornbluh, 2013, pp. 420-422). En este momento, si bien Reagan tenía al gobierno sandinista en su punto de mira, también esperaba que se diera el paso a una democracia en Chile (Morley y McGillon, 2015, pp. 199-200).

82 Télex secreto núm. 132 de la embajada de Chile en Managua al Ministerio de Relaciones Exteriores de Chile, del 6 de septiembre de 1985, fondo Países: Nicaragua. AGH-MRE, Chile.

${ }^{83}$ Véase el trabajo de Rojas Núñez (2018) para conocer los detalles de este episodio. 


\section{CONCLUSIONES}

Las relaciones entre Chile y Nicaragua demuestran que el escenario de la guerra fría latinoamericana no correspondió con la presencia en la región de dos bandos permanentemente enfrentados. La situación fue cíclica en función de las distintas coyunturas nacionales e internacionales, $y$ de las estrategias políticas implementadas por los diversos mandatarios. Tanto Chile como Nicaragua fueron dos países clave en América Latina durante las décadas de los años sesenta, setenta y ochenta. Curiosamente, su evolución ideológica fue opuesta, pues si en Nicaragua se pasó de una dictadura militar a un gobierno revolucionario, en el caso de Chile lo fue de un gobierno progresista a una dictadura militar con un proceso revolucionario como paso intermedio. A causa de sus propios procesos internos, así como por sus repercusiones internacionales, ambos países han sido estudiados en detalle. Sin embargo, la interacción entre ambos no ha sido de interés académico hasta el momento.

$\mathrm{Al}$ contrario de lo que previamente se podría suponer, los informes del Ministerio de Relaciones Exteriores de Chile demuestran que la política exterior de este país hacia Nicaragua durante la revolución sandinista fue bastante más cauta que con Cuba o incluso con otros países occidentales en los años sucesivos al golpe de Estado. Mantener un puesto de observación en Managua con el fin de conocer el transcurso de los acontecimientos políticos del país, y el objetivo de evitar un nuevo enemigo en los distintos foros de los organismos regionales e internacionales, hizo que la Junta Militar mantuviera la embajada durante seis años más tras el derrocamiento de Somoza. A pesar del cuidado de los funcionarios del propio recinto, la denuncia por parte del gobierno sandinista, así como el apoyo, confianza y buen recibimiento a los chilenos que llegaban del exilio de otros países, hizo que la tensión dominara durante todo el periodo en el que permaneció abierta. El régimen militar chileno no logró entender que el enfrentamiento era causa de la falta de libertad y la represión feroz reinante dentro de sus fronteras desde que se produjo el golpe militar contra Salvador Allende.

Dada la escasa capacidad de acción de la embajada, finalmente se decidió cerrarla. A partir de entonces, y a pesar de la existencia de relaciones, el gobierno nicaragüense apoyó indirectamente la lucha armada en Chile a través de la ayuda entregada a organizaciones como el FPMr. Asimismo, Pinochet intentó desestabilizar al FSLN barajando la posibilidad de suministrar 
misiles a la Contra, lo cual, a causa de la falta de apoyo de la Casa Blanca, no llegó a materializarse.

A causa de las buenas relaciones entre Somoza y Pinochet, así como de su colaboración en distintas áreas como la militar, ha existido el rumor de una supuesta venta de armas por parte de Pinochet a la Nicaragua somocista. Sin embargo, en los archivos consultados no ha aparecido ni una sola referencia en esta materia. La segunda mitad de la década de los años setenta, especialmente tras la llegada del presidente Carter a la Casa Blanca en enero de 1977, fue un periodo en el que Washington se distanció de las dictaduras más represivas de América Latina, lo cual se tradujo en una reducción o incluso cancelación de venta de armamento, lo cual hizo que Chile tuviera que buscar nuevos vendedores o fabricar sus propias municiones. Israel fue el país que más se benefició de esta situación, convirtiéndose en uno de los principales proveedores de ambos regímenes. ${ }^{84}$

La revolución sandinista fue la última experiencia política de la guerra fría en Latinoamérica. Las acciones encubiertas llevadas a cabo por Estados Unidos desde países vecinos dificultaron profundamente las reformas sociales y económicas en beneficio del pueblo nicaragüense. Si bien el Chile de Pinochet no participó abiertamente en esta estrategia, mientras conservó su embajada en Managua mantuvo estrecho contacto con la oposición y sirvió de plataforma para dar a conocer el discurso de oposición al sandinismo. La relación entre el régimen chileno y el gobierno sandinista terminó en 1990. A partir de ese año, la dinámica en sus relaciones se transformó radicalmente. La embajada de Chile se reabrió en Managua y empezaron a barajarse nuevas posibilidades de cooperación entre los gobiernos democráticos de Patricio Aylwin y Violeta Chamorro.

${ }^{84}$ En los últimos años han sido desclasificados algunos documentos de la cia donde se detalla la venta de armamento israelí a Chile durante el periodo de la dictadura militar. Véase el siguiente informe: "Chile: A Utilitarian Relationship with Israel". Directorate of Intelligence. Central Intelligence Agency, 5 de febrero de 1988. CIA-RDP04T00990R000100390001-8.pdf. Recuperado de https://www.cia.gov/library/readingroom/document/0001339233 [Consulta 21 de febrero de 2020.] Para las relaciones de Somoza con Israel, véase Bahbah y Butler (1986). 


\section{LISTA DE REFERENCIAS}

Ágreda Portero, J. M. y Helm, C. (2016). Solidaridad con la revolución sandinista. Naveg@mérica. Revista Electrónica Editada por la Asociación Española de Americanistas, 17. Recuperado de https://revistas.um.es/navegamerica/article/view/271921

Ágreda Portero, J. M. (2016). Un acercamiento al Comité de Solidaridad con Nicaragua en Zaragoza, España (1978-1990). Nuevo Mundo. Mundos Nuevos. DoI: https:// doi.org/10.4000/nuevomundo.69639

Armony, A. (1997). Argentina, the United States, and the anti-communist crusade in Central America, 1977-1984. Athens: Ohio University Press.

Balerini Casal, E. (2018). La asesoría militar argentina en Honduras. Diálogos. Revista Electrónica de Historia, 19(2), 198-231. DoI: https://doi.org/10.15517/dre.v19i2.31144

Bahbah B. A. y Butler, L. (1986). Israel and Latin America: The military connection. Londres: Palgrave Macmillan.

Bonnefoy Miralles, P., Pérez Silva, C. y Spotorno Lagos, A. (2009). Internacionalistas. Chilenos en la Revolución Popular Sandinista. Santiago de Chile: Editorial Latinoamericana.

Bravo Vargas, V. y Álvarez Vallejos, R. (2006). La memoria de las armas. Para una historia de los combatientes chilenos en Nicaragua. Revista Lucha Armada en la Argentina, 5.

Brands, H. (2010). Latin America's cold war. Cambridge: Harvard University Press.

Camacho Padilla, F. (2006). Los asilados de las embajadas de Europa Occidental en Chile tras el golpe militar y sus consecuencias diplomáticas: El caso de Suecia. European Review of Latin American and Caribbean Studies, 81, 21-41. DoI: https:// doi.org/10.0.71.176/erlacs.9646

Camacho Padilla, F. y Ramírez Palacio, L. (2016). Las imágenes de las guerrillas centroamericanas en las redes de la solidaridad internacional de Suecia. Naveg@ mérica. Revista Electrónica Editada por la Asociación Española de Americanistas, 17. Recuperado de https://revistas.um.es/navegamerica/article/view/271901

Cardenal, E. (2013). La revolución perdida. Managua: Anamá Ediciones.

Cortina Orero, E. (2016). La guerra por otros medios. Comunicación insurgente y proceso revolucionario en El Salvador (1970-1992). San Salvador: UCA Editores.

Cortina Orero, E. (2017). Internacionalismo y revolución sandinista: proyecciones militantes y reformulaciones orgánicas en la izquierda revolucionaria argentina. Estudios Interdisciplinarios de América Latina y el Caribe, 28(2), 80-103. Recuperado de http://eial.tau.ac.il/index.php/eial/article/view/1521 
Darnton, C. (2014). Rivalry and alliance politics in cold war Latin America. Baltimore: John Hopkins University Press.

Fermandois Huerta, J. (2005). Mundo y fin de mundo. Chile en la política mundial 19002004. Santiago de Chile: Ediciones Universidad Católica de Chile.

Ferrero Blanco, M. D. (2010). La Nicaragua de los Somoza. 1937-1979. Huelva: Universidad de Huelva/IHNCA.

Field jr., T. C., Krepp, S. y Pettinà, V. (eds.) (2020). Latin America and the global cold war. Chapel Hill: University of North Carolina Press.

Figueroa Clark, V. R. (2010). Chilean internationalism and the sandinista revolution 19781988 (Tesis inédita de doctorado). Londres: London School of Economics.

García Ferreira, R. y Taracena Arriola, A. (eds.) (2017). La guerra fría y el anticomunismo en Centroamérica. Guatemala: FLAcso-Guatemala.

Grandin, G. y Joseph, G. M. (eds.) (2010). A century of revolution: Insurgent and counterinsurgent violence during Latin America's long cold war. Durham: Duke University Press.

Harmer, T. (2011). Allende's Chile and the Inter-American cold war. Chapel Hill: University of North Carolina Press.

Helm, C. (2014a). Booming solidarity: Sandinista Nicaragua and the West German solidarity movement in the 1980s. European Review of History: Revue Européenne d'Histoire, 21(4), 597-615. DoI: https://doi.org/10.1080/13507486.2014.933179

Helm, C. (2014b). "The sons of Marx greet the sons of Sandino": West German solidarity visitors to Nicaragua sandinista. Journal of Iberian and Latin American Research, 20(2), 153-170. DoI: https://doi.org/10.1080/13260219.2014.939123

Janssens, J. (2019). Stumbling among giants: Europe's frustrated solidarity with Guatemala, 1979-1996. Bulletin of Latin American Research. Dor: https://doi.org/10.1111/ blar.13047

Joseph, G. M. y Spenser, D. (eds.) (2008). In from the cold: Latin America's new encounter with the cold war. Durham/Londres: Duke University Press.

Keller, R. (2015). Mexico's cold war: Cuba, the United States, and the legacy of the mexican revolution. Cambridge: Cambridge University Press.

Kornbluh, P. (2013). The Pinochet file: a declassified dossier on atrocity and accountability. Nueva York: The New Press.

Mandriotti, J. (2003). La última muerte de Anastasio Somoza. Buenos Aires: Alexis Editores.

Marchesi, A. (2019). Hacer la revolución. Guerrillas latinoamericanas, de los años sesenta a la caída del Muro. Buenos Aires: Siglo XXI Editores. 
Ministerio de Relaciones Exteriores (1979). Memoria del Ministerio de Relaciones Exteriores correspondiente al año de 1979. Santiago de Chile: Autor.

Ministerio de Relaciones Exteriores (1980). Memoria del Ministerio de Relaciones Exteriores correspondiente al año de 1980. Santiago de Chile: Autor.

Ministerio de Relaciones Exteriores (1983). Memoria del Ministerio de Relaciones Exteriores correspondiente al año de 1983. Santiago de Chile: Autor.

Ministerio de Relaciones Exteriores (1985). Memoria del Ministerio de Relaciones Exteriores correspondiente al año de 1985. Santiago de Chile: Autor.

Molina Jiménez, I. (2015). Repercusiones costarricenses del golpe de Estado de 1973 en Chile. Cuadernos Americanos. Nueva época, 1(151), 107-128.

Molinari, L. (2018). La dictadura argentina frente al estallido de la guerra civil salvadoreña (1977-1982): proyección continental y "experiencias compartidas”. Diálogos. Revista Electrónica de Historia, 19(2), 232-268. DoI: https://doi.org/10.15517/dre. v19i2.31173

Morley, M. y McGillon, C. (2015). Reagan and Pinochet. The struggle over U. S. policy toward Chile. Cambridge: Cambridge University Press.

Muñoz, H. (1986). Las relaciones exteriores del gobierno militar chileno. Santiago de Chile: Ediciones del Ornitorrinco.

Lisińska, M. (2018). Las "fronteras ideológicas" y la última dictadura militar en Argentina (1976-1983): el caso de las operaciones encubiertas en América Central. Anuario Latinoamericano-Ciencias Políticas y Relaciones Internacionales, 6(67), 67-84. DOI: https://doi.org/10.17951/al.2018.6.67-84

Lisińska, M. (2019). Argentine foreign policy during the military dictatorship, 1976-1983. Londres: Palgrave Macmillan.

Lozano, L. (1989). De Sandino al triunfo de la revolución. México: Siglo XXI.

Olivares Mardones, J. (2017). Guerrilla. Combatientes chilenos en Colombia, El Salvador y Nicaragua. Santiago: Ceibo Ediciones.

Pérez Silva, C. (2013a). Compañeros, a las armas: Combatientes chilenos en Centroamérica (1979-1989). Estudios Públicos, 129, 141-164.

Pérez Silva, C. (2013b). Vidas revolucionarias. Santiago de Chile: Editorial Universitaria/ CEP.

Pérez Silva, C. (2014). De la guerra contra Somoza a la guerra contra Pinochet. La experiencia internacionalista revolucionaria y la construcción de la Fuerza Militar Propia del Partido Comunista de Chile. En P. Pozzi y C. Pérez Silva (eds.), Historia oral e historia política. Izquierda y lucha armada en América Latina, 1960-1990 (pp. 213-244). Santiago de Chile: LOM Ediciones. 
Pettinà, V. (2018). Historia mínima de la guerra fría en América Latina. Ciudad de México: Colmex.

Ramírez Mercado, S. (2007). Adiós, muchachos. Madrid: Alfaguara.

Ramírez Palacio, L. (2018). Consensos trasatlánticos. El niño combatiente en las imágenes de las guerrillas salvadoreñas que circularon por Europa. Revista de Estudios Globales y Arte Contemporáneo, 5(1), 275-304. Dor: https://doi.org/10.1344/ regac2018.1.10

Rojas Núñez, L. (2018). Carrizal. Las armas del Pcch, un recodo en el camino. Santiago: LOM Ediciones.

Rostica, J. (2018). La transnacionalización de ideas: la escuela contrasubversiva de Argentina a Guatemala. Diálogos. Revista Electrónica de Historia, 19(2), 170-197. DoI: https://doi.org/10.15517/dre.v19i2.31140

Rostica et al. (2020). La masacre de El Mozote en El Salvador: una aproximación a la responsabilidad argentina.e-l@tina. Revista Electrónica de Estudios Latinoamericanos, 18(71), 61-93. Recuperado de https://publicaciones.sociales.uba.ar/index. php/elatina/article/view/5359

Sala, L. Y. (2018) Enemigos, población y guerra psicológica. Los "saberes contrasubversivos" argentinos y su (re)apropiación por los militares guatemaltecos. Diálogos. Revista Electrónica de Historia, 19(2), 140-169. DoI: https://doi.org/10.15517/dre. v19i2.31200

Sánchez Nateras, G. (2018). The Sandinista revolution and the limits of the cold war in Latin America: the dilemma of non-intervention during the Nicaraguan crisis, 1977-78. Cold War History, 18(2), 111-129. DoI: https://doi.org/10.1080/14682745.20 17.1369046

Toussaint Fernández, M. y Fernández Ampié, G. (2019). México y Centroamérica: momentos de una historia que nos une, 1960-2018. México: Instituto Mora.

Sierakowski, R. J. (2019). Sandinistas: A moral history. Notre Dame: University of Notre Dame Press.

Valdés Navarro, P. (2018). Memoria de internacionalistas chilenos. Entramado conceptual y recuperación histórica. Apuntes para el debate. Izquierdas, 38, 190-215. DOI: https://doi.org/10.4067/S0718-50492018000100190

Van Ommen, E. (2016). La Revolución Sandinista en los Países Bajos: los comités de solidaridad holandeses y Nicaragua (1977-1990). Naveg@mérica. Revista Electrónica Editada por la Asociación Española de Americanistas, 17. Recuperado de https://revistas.um.es/navegamerica/article/view/271861 
Vázquez Olivera, M. y Campos Hernández, F. (coords.) (2016). México ante el conflicto centroamericano. Testimonio de una época. Ciudad de México: Bonilla Artiga Editores.

Westad, O. A. (2007). The global cold war. Third world interventions and the making of our times. Cambridge: Cambridge University Press.

\section{OTRAS FUENTES}

\section{Archivos}

AGH-Mre Archivo General Histórico-Ministerio de Relaciones Exteriores, Chile. AIHNCA Archivo del Instituto de Historia de Nicaragua y Centroamérica, Nicaragua.

CIA Library of Declassified Materials.

Wikileaks.

\section{Hemerografía}

Página 12.

$A B C$ en el Este.

La Tercera de la Hora.

El Mercurio.

La Prensa. 